\title{
Optical and electrical properties of pressureless sintered transparent
}

$\left(\mathrm{K}_{0.37} \mathrm{Na}_{0.63}\right) \mathrm{NbO}_{3}$-based ceramics

Dong Yang, Chao Ma, Zupei Yang†, Lingling Wei, Xiaolian Chao, Zhenyu Yang, Jinglun Yang

Key Laboratory for Macromolecular Science of Shaanxi Province

School of Materials Science and Engineering, Shaanxi Normal University, Xi'an, 710062, Shaanxi,

P. R. China

Corresponding author:

Key Laboratory for Macromolecular Science of Shaanxi Province

School of Materials Science and Engineering

Shaanxi Normal University, Xi'an, 710062, Shaanxi, P. R. China

Tel: +86-29-8153-0718; Fax: +86-29-8153-0702

E-mail address: yangzp@ snnu.edu.cn 


\begin{abstract}
Lead-free $(1-x)\left(\mathrm{K}_{0.37} \mathrm{Na}_{0.63}\right) \mathrm{NbO}_{3}-x \mathrm{Ca}\left(\mathrm{Sc}_{0.5} \mathrm{Nb}_{0.5}\right) \mathrm{O}_{3}(x=0.050,0.070,0.090,0.095$ and 0.100$)$ transparent ferroelectric ceramics have been fabricated by pressureless sintering procedure. Transmittance of $0.91\left(\mathrm{~K}_{0.37} \mathrm{Na}_{0.63}\right) \mathrm{NbO}_{3}-0.09 \mathrm{Ca}\left(\mathrm{Sc}_{0.5} \mathrm{Nb}_{0.5}\right) \mathrm{O}_{3}$ ceramics sintered in sealed alumina crucible was $15 \%$ higher than those sintered unsealed in air. By increasing the content of $\mathrm{Ca}\left(\mathrm{Sc}_{0.5} \mathrm{Nb}_{0.5}\right) \mathrm{O}_{3}$, the phase structure of $\left(\mathrm{K}_{0.37} \mathrm{Na}_{0.63}\right) \mathrm{NbO}_{3}$ ceramics transformed from orthorhombic to tetragonal symmetry first and then to pseudo cubic symmetry. The 0.91( $\left(\mathrm{K}_{0.37} \mathrm{Na}_{0.63}\right) \mathrm{NbO}_{3}-0.09 \mathrm{Ca}\left(\mathrm{Sc}_{0.5} \mathrm{Nb}_{0.5}\right) \mathrm{O}_{3}$ ceramics exhibited high density $(98 \%)$, high transmittance $(60 \%)$ in the near-IR region and relatively good electrical properties $\left(\varepsilon_{\mathrm{r}}=1914, \tan \delta=\right.$ 0.037, $\left.T_{\mathrm{c}}=147{ }^{\circ} \mathrm{C}, P_{\mathrm{r}}=6.88 \mu \mathrm{C} / \mathrm{cm}^{2}, E_{\mathrm{c}}=8.49 \mathrm{kV} / \mathrm{cm}\right)$. Meanwhile, the introduction of $\mathrm{Ca}\left(\mathrm{Sc}_{0.5} \mathrm{Nb}_{0.5}\right) \mathrm{O}_{3}$ induced a composition fluctuation in the $\left(\mathrm{K}_{0.37} \mathrm{Na}_{0.63}\right) \mathrm{NbO}_{3}$ lattice and made the ceramics more relaxor-like, which would lead to a further reduction of light scattering. These results demonstrated that $0.91\left(\mathrm{~K}_{0.37} \mathrm{Na}_{0.63}\right) \mathrm{NbO}_{3}-0.09 \mathrm{Ca}\left(\mathrm{Sc}_{0.5} \mathrm{Nb}_{0.5}\right) \mathrm{O}_{3}$ could be promising lead-free transparent ferroelectric ceramics.
\end{abstract}

Keywords: Ceramics; X-ray diffraction; Ferroelectrics; Optical properties; Relaxors 


\section{Introduction}

Transparent ferroelectric ceramics are unique because of their high transparency and electro-optic effect (EO) under an electric field [1-4]. Unlike single crystals (e.g. $\mathrm{LiNbO}_{3}$ ) [5], polycrystalline transparent ceramics could be produced at low cost following well-developed technologies $[6,7]$. For example, $(\mathrm{Pb}, \mathrm{La})(\mathrm{Zr}, \mathrm{Ti}) \mathrm{O}_{3}(\mathrm{PLZT})$ ceramics showed a high photoelectric effect, and $\left[\mathrm{Pb}\left(\mathrm{Mg}_{1 / 3} \mathrm{Nb}_{2 / 3}\right) \mathrm{O}_{3}\right]-\left[\mathrm{PbTiO}_{3}\right](\mathrm{PMN}-\mathrm{PT})$ is most suitable for almost all of visible lights to mid-IR optical applications [8-10]. However, PLZT and PMN-PT exhibit some disadvantages that restrict their further development for electronic devices. These include a poor hysteresis response to electric fields, aging and fatigue, and reduction of the driving voltage [11]. In addition, both PLZT and PMN-PT ceramics contain lead, which is harmful to environment $[12,13]$. Therefore, it is desirable to develop lead-free transparent ceramics.

In recent years, sodium potassium niobate $(\mathrm{KNN})$ polycrystalline ceramics have been studied as a promising substitute for the lead-zirconate-tianate (PZT) ferroelectric materials because of their high piezoelectric constant and outstanding electrical properties [14-22]. Du [23] et al. observed a transparent phenomenon in the $0.96\left(\mathrm{~K}_{0.5} \mathrm{Na}_{0.5}\right) \mathrm{NbO}_{3}-0.04\left(\mathrm{Bi}_{0.5} \mathrm{Na}_{0.5}\right) \mathrm{TiO}_{3}$ ceramics, but the influencing factors on optical properties of the ceramics were not discussed. Chan [24] et al. employed a sol-gel method and hot-pressing sintering to prepare $\left(\mathrm{K}_{0.5} \mathrm{Na}_{0.5}\right)_{0.95} \mathrm{Li}_{0.05} \mathrm{Nb}_{0.95} \mathrm{Bi}_{0.05} \mathrm{O}_{3}$ transparent ceramics with optical transmittance reaching $60 \%$ in the near-IR region. However, the high cost of hot-pressing sintering is not adaptable to industrial applications.

Phase structures with high symmetry and high density are necessary for preparing transparent ceramics [25]. Cubic $\mathrm{Sc}_{2} \mathrm{O}_{3}$ shows excellent optical properties (high bulk refractive index $n_{\mathrm{H}}=2.0$ when $\lambda=300 \mathrm{~nm}$, and high band gap $E_{\mathrm{g}}=5.7 \mathrm{eV}$ ) [26], These properties allow $\mathrm{Sc}_{2} \mathrm{O}_{3}$ to be an 
alternative material to improve the optical properties of $\mathrm{KNN}$ ceramics. In addition, the ionic of $\mathrm{Ca}^{2+}$ $(1.34 \AA, \mathrm{CN}=12)$ is smaller than those of $\mathrm{K}^{+}(1.64 \AA, \mathrm{CN}=12)$ and $\mathrm{Na}^{+}(1.39 \AA, \mathrm{CN}=12)$. The ionic radius of $\mathrm{Sc}^{3+}(0.75 \AA, \mathrm{CN}=6)$ is larger than that of $\mathrm{Nb}^{5+}(0.64 \AA, \mathrm{CN}=6)$. The unbalanced valence and different radii of $\mathrm{Ca}^{2+}, \mathrm{K}^{+}, \mathrm{Na}^{+}, \mathrm{Sc}^{3+}$, and $\mathrm{Nb}^{5+}$ may induce some structure transformation in orthorhombic $\left(\mathrm{K}_{0.37} \mathrm{Na}_{0.63}\right) \mathrm{NbO}_{3}$ through introducing $\mathrm{Ca}\left(\mathrm{Sc}_{0.5} \mathrm{Nb}_{0.5}\right) \mathrm{O}_{3}$. In addition to possible structural transformations, potential varieties in optical and electrical properties are also of key research interest.

In this study, transparent $(1-x)\left(\mathrm{K}_{0.37} \mathrm{Na}_{0.63}\right) \mathrm{NbO}_{3}-x \mathrm{Ca}\left(\mathrm{Sc}_{0.5} \mathrm{Nb}_{0.5}\right) \mathrm{O}_{3}$ ceramics were prepared by using pressureless sintering in sealed alumina crucibles. The effects of $\mathrm{Ca}\left(\mathrm{Sc}_{0.5} \mathrm{Nb}_{0.5}\right) \mathrm{O}_{3}$ on structure, transparency, dielectric, ferroelectric and piezoelectric properties of the $\left(\mathrm{K}_{0.37} \mathrm{Na}_{0.63}\right) \mathrm{NbO}_{3}$ ceramics were investigated.

\section{Experimental}

$(1-x)\left(\mathrm{K}_{0.37} \mathrm{Na}_{0.63}\right) \mathrm{NbO}_{3}-x \mathrm{Ca}\left(\mathrm{Sc}_{0.5} \mathrm{Nb}_{0.5}\right) \mathrm{O}_{3}(0.050 \leqq x \leqq 0.100)((1-x) \mathrm{KNN}-x \mathrm{CSN})$ powders were synthesized by using solid state reaction.. Powers of $\mathrm{Na}_{2} \mathrm{CO}_{3}, \mathrm{~K}_{2} \mathrm{CO}_{3}, \mathrm{CaCO}_{3}, \mathrm{Nb}_{2} \mathrm{O}_{5}$ and $\mathrm{Sc}_{2} \mathrm{O}_{3}$ were ball-milled for $24 \mathrm{~h}$ using zirconia balls in ethanol media. The dried slurries were calcined at $950{ }^{\circ} \mathrm{C}$ for $5 \mathrm{~h}$. After re-milling for $12 \mathrm{~h}$, the calcined powders were mixed with $5 \mathrm{wt} \%$ solution of polyvinyl alcohol (PVA) and then pressed at $300 \mathrm{MPa}$ into $15 \mathrm{~mm}$ diameter pellets. After burning off the PVA, the pellets were sintered at $1220{ }^{\circ} \mathrm{C}$ for $4 \mathrm{~h}$ in a sealed alumina crucible containing the calcined powders (denoted as sealed). Pellets were also sintered at $1220{ }^{\circ} \mathrm{C}$ for $4 \mathrm{~h}$ in air (denoted as unsealed)

Phase structure characterization was performed by using X-ray diffraction (XRD, MiniFlex600, Rigaku, Tokyo, Japan, Cuk $\alpha$ ). Density was measured following the Archimedes method using 
distilled water. The fracture surface microstructure was observed by using scanning electron microscopy (SEM, SU 8020, Hitachi Company, Tokyo, Japan). Energy dispersive X-ray spectroscopy (EDS) attached to the SEM was used to analyze the chemical compositions of the fracture surface.

The samples were polished to $0.5 \mathrm{~mm}$ thickness. To obtain flatter surfaces, selected samples were additionally polished using a diamond slurry with a particle size of $0.5 \mu \mathrm{m}$. The optical transmission spectrum from 200 to $2000 \mathrm{~nm}$ was measured by using ultraviolet-visible-near infrared (UV-vis-NIR) spectroscopy (UV-3600; Shimadzu, Kyoto, Japan). For electrical measurements, silver paste was coated on both surfaces and heated at $840^{\circ} \mathrm{C}$. Dielectric properties were measured at 1,10 , 100 and $1 \mathrm{MHz}$ using an impedance analyzer (E4980A; Agilent Technologies, Santa Clara, California, USA) in a temperature range from $-200{ }^{\circ} \mathrm{C}$ to $500{ }^{\circ} \mathrm{C}$. The samples were polarized in silicone oil at $3 \mathrm{kV} / \mathrm{mm}$ for $25 \mathrm{~min}$ at $80{ }^{\circ} \mathrm{C}$. the piezoelectric coefficient $\left(d_{33}\right)$ was recorded from 1-day-aged samples using a quasistatic piezoelectric $d_{33}$ meter (ZJ-3d, Institute of Acoustics Academic Sinica, Beijing, China). Room-temperature polarization-electric field (P-E) loops were measured at $1 \mathrm{~Hz}$ by using a ferroelectric tester.

\section{Results and discussion}

The $0.91\left(\mathrm{~K}_{0.37} \mathrm{Na}_{0.63}\right) \mathrm{NbO}_{3}-0.09 \mathrm{Ca}\left(\mathrm{Sc}_{0.5} \mathrm{Nb}_{0.5}\right) \mathrm{O}_{3}$ (KNN-CSN9) ceramics were pressurelessly sintered at $1220{ }^{\circ} \mathrm{C}$ for $4 \mathrm{~h}$ in either sealed (denoted as KNN-CSN9-Sealed) or unsealed (denoted as KNN-CSN9-Unsealed) alumina crucibles.

Fig. 1 (a) shows XRD patterns of the KNN-CSN9 ceramics. Both samples show a pure perovskite phase structure with no observed impurity phases. Crystal lattice and lattice parameters $(a$, $b$ and $c$ ) have been calculated from XRD data using the least square method and are summarized in 
Table 1. No significant differences in lattice parameters are observed and the values of $a / c$ are close to 1 for both samples. This suggests that the phase structure of the two KNN-CSN9 samples is pseudo cubic.

Fig. $1(b, c)$ shows the transparent properties of the KNN-CSN9 ceramics. Fig. 1 (b) shows that a clear image can be observed through the KNN-CSN9-Sealed ceramic, suggesting a higher transparency. According to Fig. 1(c), the transmittance (T) is $60 \%$ and $45 \%$ at $1064 \mathrm{~nm}$ for the KNN-CSN9-Sealed sample and the KNN-CSN9-Unsealed sample, respectively. The transmittance difference between two samples is about $15 \%$ (Table. 1). The relative density (RD) of the KNN-CSN9-Sealed sample is $98 \%$, which is higher than that of the KNN-CSN9-Unsealed sample (95\%). The difference in transmittance between the two samples can be attributed to the heterogeneous density with less light scattering in the sealed ceramics. The relatively lower density of the KNN-CSN9-Unsealed sample may be due to the loss of $\mathrm{K}^{+}$and $\mathrm{Na}^{+}$ions during the sintering process [27]. However, sintering in the sealed alumina crucibles should prevent the loss of $\mathrm{K}^{+}$and $\mathrm{Na}^{+}$.

Fig. 2 (a, b) shows SEM images of fracture surface for the KNN-CSN9 samples. Grains of about $1 \mu \mathrm{m}$ with clear grain boundaries are observed in the KNN-CSN9-Sealed sample. The KNN-CSN9-Sealed sample also shows low porosity and a high density. A high density with fewer pores is beneficial for transmittance as the scattering of incident light is reduced. The KNN-CSN9-Unsealed sample exhibits a blurry surface of grains and grain boundaries, which may be attributed to the loss of $\mathrm{K}^{+}$and $\mathrm{Na}^{+}$. EDS data (Fig. 2(c and d)) shows the different $\mathrm{K}^{+}$and $\mathrm{Na}^{+}$ contents in the two samples. The element molar ratio of the KNN-CSN9-Sealed sample is $\mathrm{K}: \mathrm{Na}: \mathrm{Nb}$ $=0.27: 0.57: 1.00($ Fig. 2(c)). This nearer to the stoichiometric ratio $(\mathrm{K}: \mathrm{Na}: \mathrm{Nb}=0.35: 0.60: 1.00)$ and 
higher than that of the KNN-CSN9-Unsealed sample (K:Na:Nb $=0.17: 0.31: 1.00)$ (Fig. 2(d)). This demonstrates that the sealed sintering procedure is an effective approach to prevent the loss of $\mathrm{K}^{+}$and $\mathrm{Na}^{+}$.

Fig. 3 (a) shows the dielectric constant and dielectric loss measured at $1 \mathrm{MHz}$ from $40{ }^{\circ} \mathrm{C}$ to $500{ }^{\circ} \mathrm{C}$ of the KNN-CSN9 samples. The maximum dielectric constant $\left(\varepsilon_{\max }\right)$ of the KNN-CSN9-Sealed ceramic is 3279 , which is higher than that of the KNN-CSN9-Unsealed ceramic (2752) (Table 1). Polarization-electric field $(P-E)$ hysteresis loops of the KNN-CSN9 ceramics measured at $1 \mathrm{~Hz}$ at $30 \mathrm{kV} / \mathrm{cm}$ and near room temperature are shown in Fig. 3 (b). Both samples exhibit a typical ferroelectric polarization hysteresis loop. The KNN-CSN9-Sealed ceramic shows a higher remnant polarization $P_{\mathrm{r}}$ of $6.88 \mu \mathrm{C} / \mathrm{cm}^{2}$ and a lower coercive field $E_{\mathrm{c}}$ of $8.49 \mathrm{kV} / \mathrm{cm}$ than the KNN-CSN9-Unsealed sample. The KNN-CSN9-Sealed ceramic exhibits higher piezoelectric constant $d_{33}=35 \mathrm{pC} / \mathrm{N}$ than the KNN-CSN9-Unsealed ceramic $\left(d_{33}=15 \mathrm{pC} / \mathrm{N}\right)$. The better electrical properties of the KNN-CSN-Sealed ceramic can be attributed to its less defect and higher density.

Fig. $4(\mathrm{a}$ and $\mathrm{b})$ shows XRD patterns of the $(1-x) \mathrm{KNN}-x \mathrm{CSN}$ ceramics with different CSN contents. All samples exhibit a pure perovskite structure. Fig. 4 (b) plots fine scanning XRD patterns in the $2 \theta$ range from $44^{\circ}$ to $47^{\circ}$ for all samples. Two diffraction peaks $(200)_{\mathrm{O}}$ and $(020)_{\mathrm{O}}$ at $45-47^{\circ}$ are observed when $x=0.050$. When $x=0.070$, the diffraction peaks change to $(002)_{\mathrm{T}}$ and $(200)_{\mathrm{T}}$, only one peak (200) is observed, suggesting that the structure of the $(1-x) \mathrm{KNN}-x \mathrm{CSN}$ ceramics has transformed firstly from orthorhombic to tetragonal symmetry and then to a pseudo cubic symmetry. This may be attributed to the replacement of the octahedral center $\mathrm{Nb}^{5+}(0.64 \AA)$ by $\operatorname{Sc}^{3+}(0.75 \AA)$, expanding of oxygen octahedral, and the replacement of $\mathrm{K}^{+}(1.64 \AA)$ and $\mathrm{Na}^{+}(1.39 \AA)$ by $\mathrm{Ca}^{2+}(1.34 \AA)$. 
To further confirm the effect of CSN content on the crystal lattice, lattice parameters of $a, b, c$ and the ratio of $a / c$ were calculated from the XRD data using the least square method (Table 2). With increasing content of CSN, the value of $a / c$ varied from 1.0434 to 0.9900 . This suggests that a phase transformation occurs from an orthorhombic to a pseudo cubic. The pseudo cubic phase structure at $0.090 \leqq x \leqq 0.100$ eliminates the optical scattering, similar to that observed in $\mathrm{Pb}_{0.91} \mathrm{La}_{0.09}\left(\mathrm{Zr}_{0.65} \mathrm{Ti}_{0.35}\right) \mathrm{O}_{3}$ ceramics [1]. The cubic-like structure can reduce the birefringence, and leads to higher light transmittance. In addition, with increasing content of CSN, the RD of the $(1-x) \mathrm{KNN}-x \mathrm{CSN}$ ceramics increases when $x \leqq 0.090$ and then decreases when $x>0.090$. The maximum RD of the $(1-x) \mathrm{KNN}-x \mathrm{CSN}$ ceramics is $98 \%$ when $x=0.090$. These results indicate that CSN has a positive effect on the densification of the samples.

The optical properties of the $(1-x) \mathrm{KNN}-x \mathrm{CSN}$ ceramics are shown in Fig. 5. As observed in Fig. 5 (a), as $x$ is increased from 0.050 to 0.100 , the optical transparency initially increases and then decreases. When $x=0.090$, the sample shows the maximum transmittance. This is in accordance with the RD results. From the results shown in Table 2 and Fig. 5 (a), it can be stated that with a higher structural symmetry and higher ceramic density, then the greater transmittance is achieved. Fig. 5 (b) shows the optical transmittance spectrum of the $(1-x) \mathrm{KNN}-x \mathrm{CSN}$ ceramics measured from 200-2000 nm. The $(1-x) \mathrm{KNN}_{-}-x \mathrm{CSN}$ ceramics show excellent optical performance above $780 \mathrm{~nm}$. The $(1-x) \mathrm{KNN}-x \mathrm{CSN}$ ceramics with $x=0.090$ also has a superior transmittance, as shown in Fig. 5 (c). The transmittance of $60 \%$ for KNN-CSN9 ceramic at $1064 \mathrm{~nm}$ could be used in Nd:YAG solid lasers applications.

A strong absorption is also observed in the near ultraviolet light $(390 \mathrm{~nm})$ due to the transition of electrons from the valance band to the conduction band. According to the Tauc equation, the 
optical band gap energy $\left(E_{\mathrm{g}}\right)$ can be estimated from the absorption spectra [28, 29]. For a direct transition, the relationship between $E_{\mathrm{g}}$ and the absorption coefficient $\alpha$ is given by:

$$
(\alpha h v)^{2}=A\left(h v-E_{g}\right),
$$

where $v$ is the photon frequency, $h$ is Planck's constant and $A$ is a constant. The absorption coefficient can be calculated from the transmittance (T) by

$$
\alpha=\frac{1}{t} \ln \left(\frac{1}{T}\right)
$$

where $t$ is the thickness of the sample. Therefore, $E_{\mathrm{g}}$ was determined for the $(1-x) \mathrm{KNN}-x \mathrm{CSN}$ ceramics by plotting $(\alpha h v)^{2}$ versus $h v$ and extrapolating the linear portion of the curve to zero, as shown in Fig. 6 (a-e). The calculated $E_{g}$ of the $(1-x) \mathrm{KNN}-x \mathrm{CSN}$ ceramics (when $x=0.050,0.070$, $0.090,0.095$ and 0.100 ) is $2.96 \mathrm{eV}, 3.02 \mathrm{eV}, 3.04 \mathrm{eV}, 3.00 \mathrm{eV}$ and $2.96 \mathrm{eV}$, respectively. Fig. 6 (f) shows the $E_{\mathrm{g}}$ of the $(1-x) \mathrm{KNN}-x \mathrm{CSN}$ ceramics with $x$. The highest $E_{g}=3.04 \mathrm{eV}$ of the KNN-CSN9 ceramic is in good agreement to the previously reported value $(3.09 \mathrm{eV})$ of for the highest transmittance in $\left(\mathrm{K}_{0.5} \mathrm{Na}_{0.5}\right)_{0.95} \mathrm{Li}_{0.05} \mathrm{Nb}_{0.95} \mathrm{Bi}_{0.05} \mathrm{O}_{3}$ transparent ceramic [24]. This suggests that the band gap of the $0.91\left(\mathrm{~K}_{0.37} \mathrm{Na}_{0.63}\right) \mathrm{NbO}_{3}-0.09 \mathrm{Ca}\left(\mathrm{Sc}_{0.5} \mathrm{Nb}_{0.5}\right) \mathrm{O}_{3}$ ceramic corresponds to the transition from the top of the valence bands occupied by $\mathrm{O}_{2 \mathrm{p}}$ electron state to the bottom of the conduction bands which is dominated by the empty $\mathrm{Nb}_{4 \mathrm{~d}}$ electron state.

Fig. 7 (a-e) shows the temperature dependence of dielectric permittivity and dielectric loss of the $(1-x) \mathrm{KNN}-x \mathrm{CSN}$ ceramics at different frequencies measured from -200 to $500{ }^{\circ} \mathrm{C}$. A phase transition of orthorhombic-tetragonal ( $\left.\mathrm{T}_{\mathrm{O}-\mathrm{T}}\right)$ is observed is Fig. 7 (a) at about $150{ }^{\circ} \mathrm{C}$. In Fig. 7 (b), the phase transition, at about $0{ }^{\circ} \mathrm{C}$, of $\mathrm{T}_{\mathrm{O}-\mathrm{T}}$ cannot be observed in the KNN-CSN7 ceramic. The phase transition of $\mathrm{T}_{\mathrm{O}-\mathrm{T}}$ then completely disappears in the KNN-CSN9 ceramic, as shown in Fig. 7 (c). This implies that the structure changes to the pseudo cubic phase. A similar phenomenon has also been 
observed by Yang [30] et al. who added Ta to $\left(\mathrm{K}_{0.44} \mathrm{Na}_{0.52} \mathrm{Li}_{0.04}\right)\left(\mathrm{Nb}_{0.96} \mathrm{Sb}_{0.04}\right) \mathrm{O}_{3}$. The dielectric constant is also seen to decrease slightly with increasing frequency. This phenomenon implies that the ceramics are relaxor-like. With increasing content of CSN the Curie temperature $\left(T_{\mathrm{c}}\right)$ decreases from $285{ }^{\circ} \mathrm{C}$ to $124{ }^{\circ} \mathrm{C}$. In addition, the $\varepsilon_{\max }$ initially increases and then decreases with increasing CSN content. The KNN-CSN9 has the highest $\varepsilon_{\max }$ value(3279) and has a $T_{\mathrm{c}}$ of $147^{\circ} \mathrm{C}$.

It is well known that above Curie temperature, the dielectric permittivity of a normal ferroelectric should obey the Curie-Weiss law:

$$
\begin{aligned}
& \varepsilon=\frac{C}{T-T_{C W}}, \\
& \Delta T_{m}=T_{B}-T_{m}, \\
& \frac{1}{\varepsilon}-\frac{1}{\varepsilon_{m}}=\frac{\left(T-T_{m}\right)^{\gamma}}{C},
\end{aligned}
$$

where $C$ is the Curie-Weiss constant, $T_{\mathrm{CW}}$ is the Curie-Weiss temperature, $\mathrm{T}_{\mathrm{B}}$ is the Burns' temperature (determined from the inverse dielectric permittivity [31]), $T_{\mathrm{m}}$ is the temperature of the maximum dielectric permittivity and $\gamma$ is a diffusion coefficient [32]. Normal ferroelectrics, relaxor-like ferroelectrics and ideal relaxor ferroelectrics are identified when $\gamma=1,1<\gamma<2$, and $\gamma=2$ respectively. Plots of inverse dielectric permittivity versus temperature at $1 \mathrm{MHz}$ are shown in Fig. 8 (a-e) and are used to obtain the value of $T_{\mathrm{CW}}$. It is found that with increasing CSN content. the dielectric permittivity of the $(1-x) \mathrm{KNN}-x \mathrm{CSN}$ ceramics deviates from the Curie-Weiss law. An increase in $\Delta T_{\mathrm{m}}$ is observed with increasing $x$, and a maximum value of $161^{\circ} \mathrm{C}$ is obtained when $x=$ 0.090 (Table 3.). This indicates that the relaxor behavior is enhanced with increasing CSN content.

Fig. 8 (f) shows the plots of $\log \left(1 / \varepsilon-1 / \varepsilon_{\mathrm{m}}\right)$ as a function of $\log \left(T-T_{\mathrm{m}}\right)$ at $1 \mathrm{MHz}$ for the $(1-x)$ $\mathrm{KNN}-x \mathrm{CSN}$ ceramics. A linear relationship is observed for all samples. The slope of the fitting curve is used to determine the $\gamma$ value, and can be used to confirm the effect of the CSN content on the 
relaxor behavior of the $(1-x) \mathrm{KNN}-x \mathrm{CSN}$ ceramics. The $\gamma$ value increases from 1.68 to 1.85 with increasing CSN content. The fitting results obtained by the Curie-Weiss law are listed in Table 3 . The result demonstrates that the $(1-x) \mathrm{KNN}-x \mathrm{CSN}$ ceramics exhibit relaxor behavior. The relaxational behavior in relaxor ferroelectrics can be explained by the composition fluctuation theory $[33,34]$. Because of their large ionic radii, $\mathrm{Na}^{+}(1.39 \AA), \mathrm{K}^{+}(1.64 \AA)$ and $\mathrm{Ca}^{2+}(1.34 \AA)$ in the $(1-x) \mathrm{KNN}-x \mathrm{CSN}$ ceramics occupy the A site of $\mathrm{ABO}_{3}$ perovskite structure. $\mathrm{Ca}^{2+}$ possesses a different valence and ionic radius to $\mathrm{Na}^{+}$and $\mathrm{K}^{+}$, resulting in the formation of local electric fields. These local structure distortions cause local charge imbalance and local elastic fields. Similar phenomenon also occurs at the $\mathrm{B}$ site of the $\mathrm{ABO}_{3}$ perovskite structure, where $\mathrm{Nb}^{5+}(0.64 \AA)$ and $\mathrm{Sc}^{3+}(0.75 \AA)$ exhibit different valences and ionic radii. These models are based on the local distortion of the crystal structure, leading to the composition fluctuation, and resulting in the relaxor behavior.

Fig. 9 (a and b) shows polarization-electric field (P-E) hysteresis loops of the (1-x)KNN-xCSN ceramics measured at $1 \mathrm{~Hz}$ at $30 \mathrm{kV} / \mathrm{cm}$ near room temperature. The KNN-CSN5 ceramic exhibits a typical hysteresis loop with a coercive field $\left(E_{\mathrm{c}}\right)$ of $10.97 \mathrm{kV} / \mathrm{cm}$ and remnant polarization $\left(P_{\mathrm{r}}\right)$ of $9.39 \mu \mathrm{C} / \mathrm{cm}^{2}$. With increasing CSN content, $E_{\mathrm{c}}$ and $P_{\mathrm{r}}$ decrease slowly when $0.050 \leqq x \leqq 0.090$. A more rapid decrease is then observed when $0.090<x \leqq 0.100$ (Fig. 9 (b)), which may be attributed to the composition fluctuation. Fig. 9 (c) shows piezoelectric constants $d_{33}$ of the $(1-x) \mathrm{KNN}-x \mathrm{CSN}$ ceramics. For all samples, $d_{33}$ decreases slowly when $x \leqq 0.090$ and decreases more rapidly when $0.090<x \leqq 0.100$. The highest piezoelectric coefficient is $52 \mathrm{pC} / \mathrm{N}$ for KNN-CSN5. The decrease in $d_{33}$ can be attributed to the composition fluctuation and the structure transformation.

\section{Conclusions}


Lead-free transparent $(1-x) \mathrm{KNN}-x \mathrm{CSN}$ ceramics with remarkable optical transparency were prepared by using a pressureless sintering method. The presence of CSN induced phase transformations from an orthorhombic to a pseudo cubic symmetry, via a tetragonal phase. This transition might reduce optical anisotropy and enhance the optical transparency of the ceramics. The introduction of $\mathrm{Ca}^{2+}$ and $\mathrm{Sc}^{3+}$ induced a composition fluctuation, making the ceramics more relaxor-like. This resulted in the elimination of light scattering due to the presence of the pseudo cubic phase with high symmetry. Of all samples, KNN-CSN9 ceramics showed the highest density $(98 \%)$, greatest transmittance $(60 \%)$ in the near-IR region, and relatively good electrical properties $\left(\varepsilon_{\mathrm{r}}=1914, \tan \delta=0.037, T_{\mathrm{c}}=147^{\circ} \mathrm{C}, P_{\mathrm{r}}=6.88 \mu \mathrm{C} / \mathrm{cm}^{2}, E_{\mathrm{c}}=8.49 \mathrm{kV} / \mathrm{cm}\right)$. These results demonstrate that the $0.91\left(\mathrm{~K}_{0.37} \mathrm{Na}_{0.63}\right) \mathrm{NbO}_{3}-0.09 \mathrm{Ca}\left(\mathrm{Sc}_{0.5} \mathrm{Nb}_{0.5}\right) \mathrm{O}_{3}$ ceramic could be promising lead-free transparent ferroelectric ceramics. 


\section{Acknowledgments}

This work has been supported by the National Science Foundation of China (NSFC) (Grant No.51572163, 51577111, 51172136, 21401123 and 51107077), the Fundamental Research Funds for the Central Universities (Program No.GK201403006, No.GK201402061, No.GK201301002, GK201101003 and GK201101004), Innovation Funds of Graduate Programs, Shaanxi Normal University (Grant No.X2014YB05), Scientific and Technology Research Project in Xi'an [Program No. CXY1342(4)]. 


\section{References}

[1] J. G. Wu, D. Q. Xiao, J. G. Zhu, Potassium-sodium niobate lead-free piezoelectric materials: past, present, and future of phase boundaries, Chem. Rev. 115 (2015) 2559-2595.

[2] X. P. Wang, J. G. Wu, D. Q. Xiao, J. G. Zhu, X. J. Cheng, T. Zheng, B. Y. Zhang, X. J. Lou, X. J. Wang, Giant piezoelectricity in potassium-sodium niobate lead-free ceramics, J. Am. Chem. Soc. 136 (2014) 2905-2910.

[3] S. F. Wang, J. Zhang, D. W. Luo, F. Gu, D. Y. Tang, Z. L. Dong, G. E. B. Tan, W. X. Que, T. S. Zhang, S. Li, L.B. Kong, Transparent ceramics: processing, materials and applications, Prog. Solid. State. Chem. 41 (2013) 20-54.

[4] A. Krell, J. Klimke, T. Hutzler, Transparent compact ceramics: inherent physical issues, Opt. Mater. 31 (2009) 1144-1150.

[5] R. V. A. Murthy, K. S. Bartwal, K. Lal, Growth of nearly perfect $\mathrm{LiNbO}_{3}$ single crystals, Mater. Sci. Eng. B 18 (1993) L4-L6.

[6] R. Johnson, P. Biswas, P. Ramavath, R. S. Kumar, G. Padmanabham, Transparent polycrystalline ceramics: an overview, Trans. Indian Ceram. Soc. 71 (2012) 73-85.

[7] S. Tanaka, T. Takahashi, K. Uematsu, Fabrication of transparent crystal-oriented polycrystalline strontium barium niobate ceramics for electro-optical application, J. Eur. Ceram. Soc. 34 (2014) 3723-3728.

[8] G. H. Haertling, C. E. Land, Recent improvements in the optical and electrooptic properties of PLZT ceramics, Ferroelectrics 3 (1972) 269-280.

[9] G. S. Snow, Fabrication of transparent electrooptic PLZT ceramics by atmosphere sintering, J. Am. Ceram. Soc. 56 (1973) 91-96. 
[10] K. K. Li, Y. Lu, W. Wang, Electro-optic ceramic material and device, U.S. Patent 6, 890, 874, 2005.

[11] A. Sternberg, Transparent ferroelectric ceramics: properties and applications, Ferroelectrics 91 (1989) 53-67.

[12] G. H. Haertling, Ferroelectric ceramics: history and technology, J. Am. Ceram. Soc. 82 (1999) 797-818.

[13] P. K. Panda, Review: environmental friendly lead-free piezoelectric materials, J. Mater. Sci. 44 (2009) 5049-5062.

[14] Y. Saito, H. Takao, T. Tani, T. Nonoyama, K. Takatori, T. Homma, T. Nagaya, M. Nakamura, Lead-free piezoceramics, Nature 432 (2004) 84-87.

[15] M. Ichikia, L. Zhang, M. Tanaka, R. Maeda, Electrical properties of piezoelectric sodium-potassium niobate, J. Eur. Ceram. Soc. 24 (2004) 1693-1697.

[16] J. Rödel, W. Jo, K. T. P. Seifert, E. M. Anton, T. Granzow, D. Damjanovic, Perspective on the development of lead-free piezoceramics, J. Am. Ceram. Soc. 92 (2009) 1153-1177.

[17] Y. F. Chang, Z. P. Yang, Y. T. Hou, Z. H. Liu, Z. L. Wang, Effects of Li content on the phase structure and electrical properties of lead-free $\left(\mathrm{K}_{0.46-x / 2} \mathrm{Na}_{0.54-x / 2} \mathrm{Li}_{x}\right)\left(\mathrm{Nb}_{0.76} \mathrm{Ta}_{0.20} \mathrm{Sb}_{0.04}\right) \mathrm{O}_{3}$ ceramics, Appl. Phys. Lett. 90 (2007) 232905.

[18] Y. F. Chang, Z. P. Yang, L. R. Xiong, Z. H. Liu, Z. L. Wang, Phase structure, microstructure, and electrical eroperties of $\mathrm{Sb}$-modified $(\mathrm{K}, \mathrm{Na}, \mathrm{Li})(\mathrm{Nb}, \mathrm{Ta}) \mathrm{O}_{3}$ piezoelectric ceramics, J. Am. Ceram. Soc. 91 (2008) 2211-2216.

[19] J. F. Li, K. Wang, F. Y. Zhu, L. Q. Cheng, F. Z. Yao, (K, Na) $\mathrm{NbO}_{3}$-based lead-free piezoceramics: fundamental aspects, processing technologies, and remaining challenges, J. Am. 
Ceram. Soc. 96 (2013) 3677-3696.

[20] X. P. Wang, J. G. Wu, D. Q. Xiao, X. J. Cheng, T. Zheng, B. Y. Zhang, X. J. Lou, J. G. Zhu, Large $d_{33}$ in $(\mathrm{K}, \mathrm{Na})(\mathrm{Nb}, \mathrm{Ta}, \mathrm{Sb}) \mathrm{O}_{3}-(\mathrm{Bi}, \mathrm{Na}, \mathrm{K}) \mathrm{ZrO}_{3}$ lead-free ceramics, J. Mater. Chem. A 2 (2014) 4122-4126.

[21] J. G. Wu, J. Q. Xiao, T. Zheng, X. P. Wang, X. J. Cheng, B. Y. Zhang, D. Q. Xiao, J. G. Zhu, Giant piezoelectricity of $(\mathrm{K}, \mathrm{Na})(\mathrm{Nb}, \mathrm{Sb}) \mathrm{O}_{3}-(\mathrm{Bi}, \mathrm{Na}, \mathrm{K}, \mathrm{Pb}) \mathrm{ZrO}_{3}$ ceramics with rhombohedral-tetragonal (RT) phase boundary, Scripta Mater. 88 (2014) 41-44.

[22] X. P. Wang, J. G. Wu, D. Q. Xiao, J. G. Zhu, X. J. Cheng, T. Zheng, B. Y. Zhang, X. J. Lou, X. J. Wang, Giant piezoelectricity in potassium-sodium niobate lead-free ceramics, J. Am. Chem. Soc. 136 (2014) 2905-2910.

[23] H. L. Du, W. C. Zhou, D. M. Zhu, L. Fa, S, B. Qu, Y. Li, Z. B. Pei, Sintering characteristic, microstructure, and dielectric relaxor behavior of $\left(\mathrm{K}_{0.5} \mathrm{Na}_{0.5}\right) \mathrm{NbO}_{3}-\left(\mathrm{Bi}_{0.5} \mathrm{Na}_{0.5}\right) \mathrm{TiO}_{3}$ lead-free ceramics, J. Am. Ceram. Soc. 91 (2008) 2903-2909.

[24] F. L. Li, K. W. Kwok, Fabrication of transparent electro-optic $\left(\mathrm{K}_{0.5} \mathrm{Na}_{0.5}\right)_{1-x} \mathrm{Li}_{x} \mathrm{Nb}_{1-x} \mathrm{Bi}_{x} \mathrm{O}_{3}$ lead-free ceramics, J. Eur. Ceram. Soc. 33 (2013) 123-130.

[25] G. R. Li, W. Ruan, J. T. Zeng, H. R. Zeng, L. Y. Zheng, L. S. Kamzina, Y. Kopylov, V. Kravchenko, The effect of domain structures on the transparency of PMN-PT transparent ceramics, Opt. Mater. 35 (2013) 722-726.

[26] Y. Wang, B. Lu, X. Sun, T. Sun, H. Xu, Synthesis of nanocrystalline $\mathrm{Sc}_{2} \mathrm{O}_{3}$ powder and fabrication of transparent $\mathrm{Sc}_{2} \mathrm{O}_{3}$ ceramics, Adv. Appl. Ceram. 110 (2011) 95-98.

[27] Q. Zhang, B. P. Zhang, H. T. Li, P. P. Shang, Effects of Na/K ratio on the phase structure and electrical properties of $\mathrm{Na}_{x} \mathrm{~K}_{1-x} \mathrm{NbO}_{3}$ lead-free piezoelectric ceramics, Rare Metals 29 (2010) 
220-225.

[28] A. El-Korashy, A. A. El-Fadl, Temperature dependence of the optical band gap of nearly perfect $\mathrm{K}_{2} \mathrm{ZnCl}_{4}$ single crystals in the ferroelectric phase, Physica B 271 (1999) 205-211.

[29] Z. Wang, H. S. Gu, Y. M. Hu, K. Yang, M. Z. Hu, D. Zhou, J. G. Guan, Synthesis, growth mechanism and optical properties of $(\mathrm{K}, \mathrm{Na}) \mathrm{NbO}_{3}$ nanostructures, CrystEngComm 12 (2010) $3157-3162$.

[30] Z. P. Yang, Y. F. Chang, L. L. Wei, Phase transitional behavior and electrical properties of lead-free $\left(\mathrm{K}_{0.44} \mathrm{Na}_{0.52} \mathrm{Li}_{0.04}\right)\left(\mathrm{Nb}_{0.96-x} \mathrm{Ta}_{x} \mathrm{Sb}_{0.04}\right)$, Appl. Phys. Lett. 90 (2007) 042911.

[31] C. J. Stringer, T. R. Shout, C. A. Randall, High-temperature perovskite relaxor ferroelectrics: A comparative study, J. Appl. Phys. 101 (2007) 054107.

[32] K. Uchino, S. Nomura, Critical exponents of the dielectric constants in diffused-phase-transition crystals, Ferroelectrics 44 (1982) 55.

[33] I. W. Chen, Structural origin of relaxor ferroelectrics-revisited, J. Phys. Chem. Sol. 61 (2000) $197-208$

[34] A. A. Bokov, Z. G. Ye, Recent progress in relaxor ferroelectrics with perovskite structure, J. Mater. Sci. 41 (2006) 31-52. 


\section{Figure captions}

Fig. 1. (a) XRD patterns, (b) photograph and (c) optical transmission characteristics of the KNN-CSN9 ceramics.

Fig. 2. SEM micrographs of fracture surfaces of the KNN-CSN-Sealed (a) and KNN-CSN9-Unsealed (b) samples, EDS spectrum of surfaces of the KNN-CSN9-Sealed (c) and KNN-CSN9-Unsealed (d) samples.

Fig. 3. (a) Temperature dependences of dielectric constant at $1 \mathrm{MHz}$, (b) polarization-electric field (P-E) hysteresis loops of the KNN-CSN9 ceramics sintering at different conditions.

Fig. 4. XRD patterns of the $(1-x) \mathrm{KNN}-x \mathrm{CSN}$ ceramics sintered at $1220^{\circ} \mathrm{C}$ for $4 \mathrm{~h}$.

Fig. 5. (a) Photograph and (b, c) optical transmission characteristics of the (1-x)KNN-xCSN transparent ceramics.

Fig. 6. Plots of $(\alpha h v)^{2}$ versus $h v$, energy band gap $E_{g}$ for the (1-x)KNN-xCSN ceramics.

Fig. 7. (a-e)Temperature dependences of dielectric constant and dielectric loss at different frequencies $(1 \mathrm{kHz}, 10 \mathrm{kHz}, 100 \mathrm{kHz}, 1 \mathrm{MHz})$ of the $(1-x) \mathrm{KNN}-x \mathrm{CSN}$ ceramics, (f) Curie temperature $\left(T_{\mathrm{c}}\right)$ and the max dielectric constant $\left(\varepsilon_{\max }\right)$ at $1 \mathrm{MHz}$ of the $(1-x) \mathrm{KNN}-x \mathrm{CSN}$ ceramics.

Fig. 8. (a-e) Inverse dielectric permittivity at $1 \mathrm{MHz}$ as a function of temperature for the $(1-x) \mathrm{KNN}-x \mathrm{CSN}$ ceramics; (f) $\log \left(1 / \varepsilon-1 / \mathcal{E}_{\mathrm{m}}\right)$ as a function of $\log \left(T-T_{\mathrm{m}}\right)$ at $1 \mathrm{MHz}$ for the $(1-x) \mathrm{KNN}-x \mathrm{CSN}$ ceramics.

Fig. 9. (a) $P$-E hysteresis loops, (b) remnant polarization $P_{\mathrm{r}}$ and coercive field $E_{\mathrm{c}}$, (c) piezoelectric constants $d_{33}$ of the (1-x) KNN-xCSN ceramics. 
Tab. 1. Lattice parameters, relative density (RD), electric and ferroelectric properties of the KNN-CSN9 ceramics.

\begin{tabular}{|c|c|c|c|c|c|c|c|c|c|c|c|}
\hline \multirow{2}{*}{ Sample } & \multicolumn{4}{|c|}{ Lattice parameters } & \multirow{2}{*}{ RD } & \multirow{2}{*}{$\begin{array}{c}\text { T@1064 } \\
\text { nm }\end{array}$} & \multirow[b]{2}{*}{$\varepsilon_{\max }$} & \multirow{2}{*}{$\begin{array}{c}\boldsymbol{T}_{\mathbf{c}} \\
\left({ }^{\circ} \mathbf{C}\right) \\
\end{array}$} & \multirow{2}{*}{$\begin{array}{c}P_{\mathrm{r}} \\
\left(\mu \mathrm{C} / \mathbf{c m}^{2}\right)\end{array}$} & \multirow{2}{*}{$\begin{array}{c}E_{\mathrm{c}} \\
(\mathrm{kV} / \mathrm{cm})\end{array}$} & \multirow{2}{*}{$\begin{array}{c}d_{33} \\
(\mathrm{pC} / \mathrm{N})\end{array}$} \\
\hline & $\mathbf{a}(\AA)$ & $\mathbf{b}(\AA)$ & c $(\AA)$ & $\mathbf{a} / \mathbf{c}$ & & & & & & & \\
\hline Sealed & 3.9534 & 3.9295 & 3.8936 & 1.0154 & $98 \%$ & $59.93 \%$ & 3279 & 147 & 6.88 & 8.49 & 35 \\
\hline Unsealed & 3.9510 & 3.9422 & 3.9310 & 1.0051 & $95 \%$ & $45.25 \%$ & 2752 & 134 & 4.35 & 9.61 & 15 \\
\hline
\end{tabular}

Tab. 2. Lattice parameters and relative density (RD) of the $(1-x) \mathrm{KNN}-x \mathrm{CSN}$ ceramics.

\begin{tabular}{lccccc}
\hline & \multicolumn{4}{c}{ Lattice parameters } & \multirow{2}{*}{$\mathbf{R D}$} \\
\cline { 2 - 5 } & $\mathbf{a}(\AA \mathbf{\AA})$ & $\mathbf{b}(\AA)$ & $\mathbf{c}(\mathbf{\AA})$ & $\mathbf{a} / \mathbf{c}$ & \\
\hline$x=0.050$ & 4.0264 & 3.9173 & 3.8588 & 1.0434 & $95 \%$ \\
$x=0.070$ & 3.9833 & 3.9292 & 3.8841 & 1.0255 & $93 \%$ \\
$x=0.090$ & 3.9534 & 3.9295 & 3.8936 & 1.0154 & $98 \%$ \\
$x=0.095$ & 3.9482 & 3.9502 & 3.9513 & 0.9992 & $97 \%$ \\
$x=0.010$ & 3.9326 & 3.9529 & 3.9724 & 0.9900 & $97 \%$ \\
\hline
\end{tabular}

Tab. 3. Curie-Weiss temperature $\left(T_{\mathrm{CW}}\right)$, temperature above which the dielectric constant follows the Curie-Weiss law $\left(T_{\mathrm{B}}\right)$, deviation $\left(\Delta T_{\mathrm{m}}\right)$,

Curie-Weiss constant (C), and diffuseness $(\gamma)$ for the $(1-x) \mathrm{KNN}-x \mathrm{CSN}$ ceramics at $1 \mathrm{MHz}$.

\begin{tabular}{cccccc}
\hline & \multicolumn{5}{c}{$(\mathbf{1 - x}) \mathbf{K N N}-\boldsymbol{x} \mathbf{C S N}$} \\
\cline { 2 - 6 } & $x=0.050$ & $x=0.070$ & $x=0.090$ & $x=0.095$ & $x=0.010$ \\
\hline$T_{\mathrm{CW}}\left({ }^{\circ} \mathrm{C}\right)$ & 274 & 225 & 183 & 175 & 148 \\
$C \sim 10^{5}\left({ }^{\circ} \mathrm{C}\right)$ & 1.55 & 1.47 & 1.46 & 1.48 & 1.50 \\
$T_{\mathrm{B}}\left({ }^{\circ} \mathrm{C}\right)$ & 340 & 320 & 309 & 297 & 268 \\
$\Delta T_{\mathrm{m}}=T_{\mathrm{B}}-T_{\mathrm{m}}\left({ }^{\circ} \mathrm{C}\right)$ & 46 & 103 & 161 & 159 & 154 \\
$\gamma$ & 1.68 & 1.78 & 1.85 & 1.83 & 1.80 \\
\hline
\end{tabular}




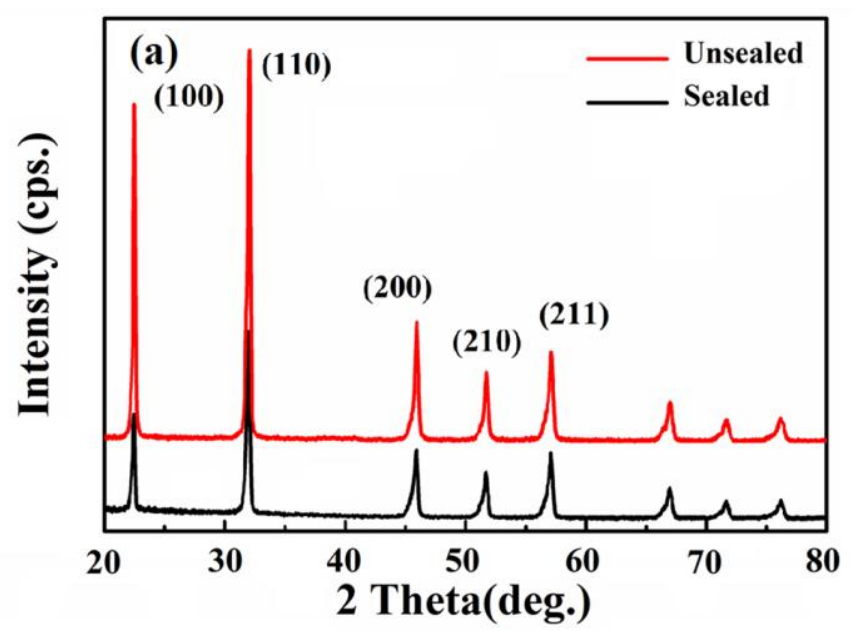

(b)

SHAANXI NORMAL UNIVERSITY SHAANXI MAL 'ERSITY SHAANXI NORMAL UNIVERSITY

Sealed Unsealed

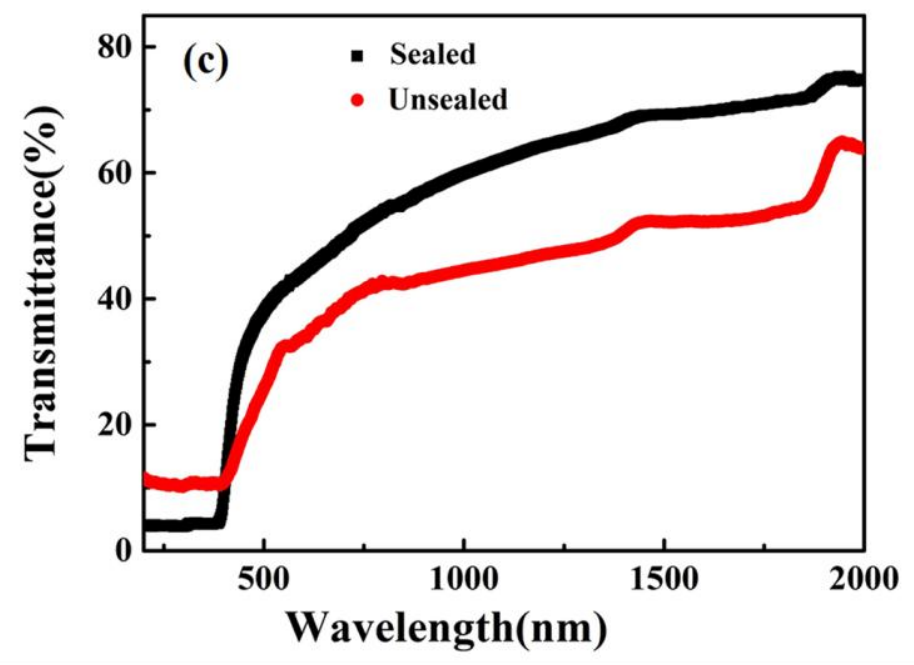

Figure 1 

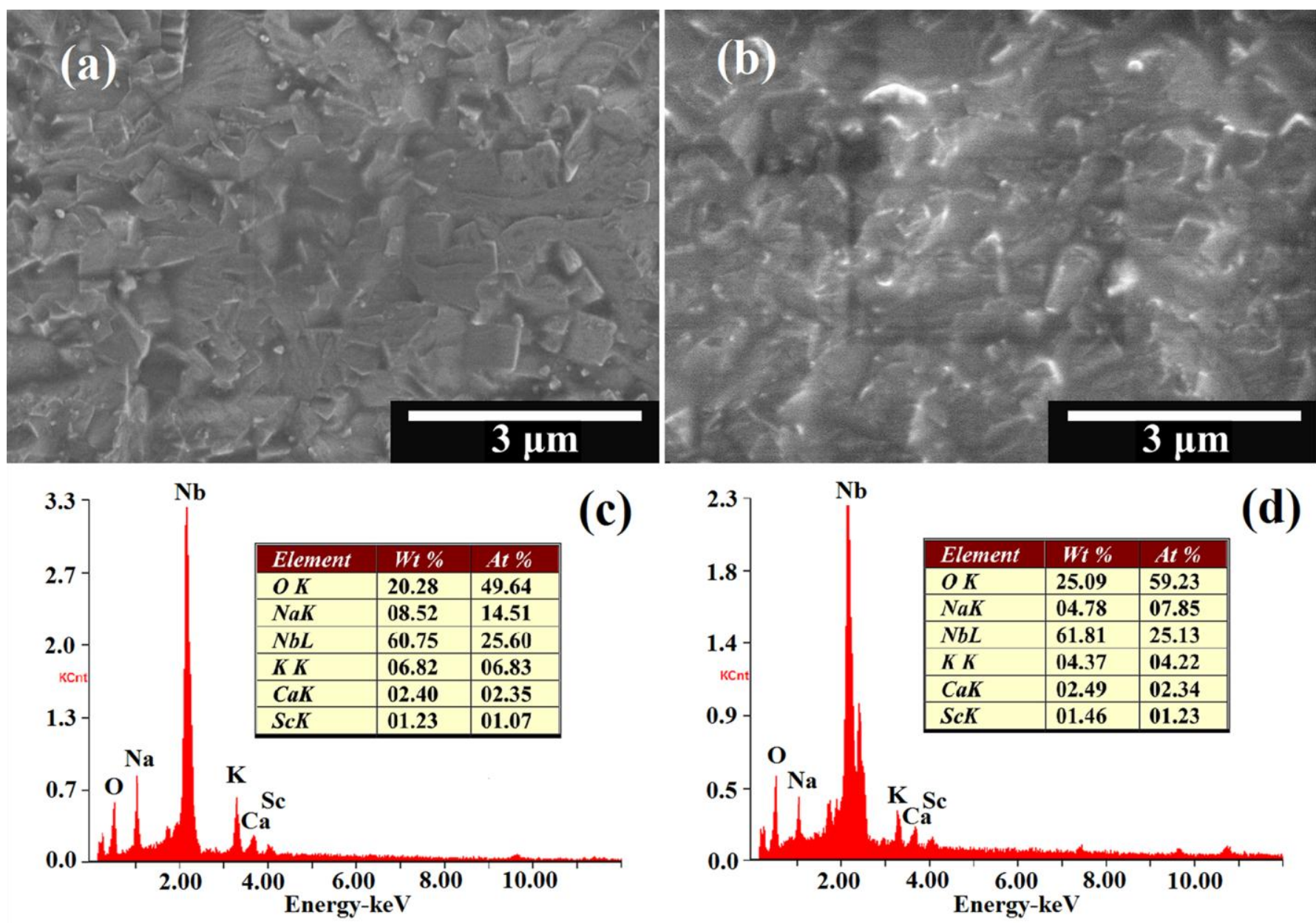

Figure 2 

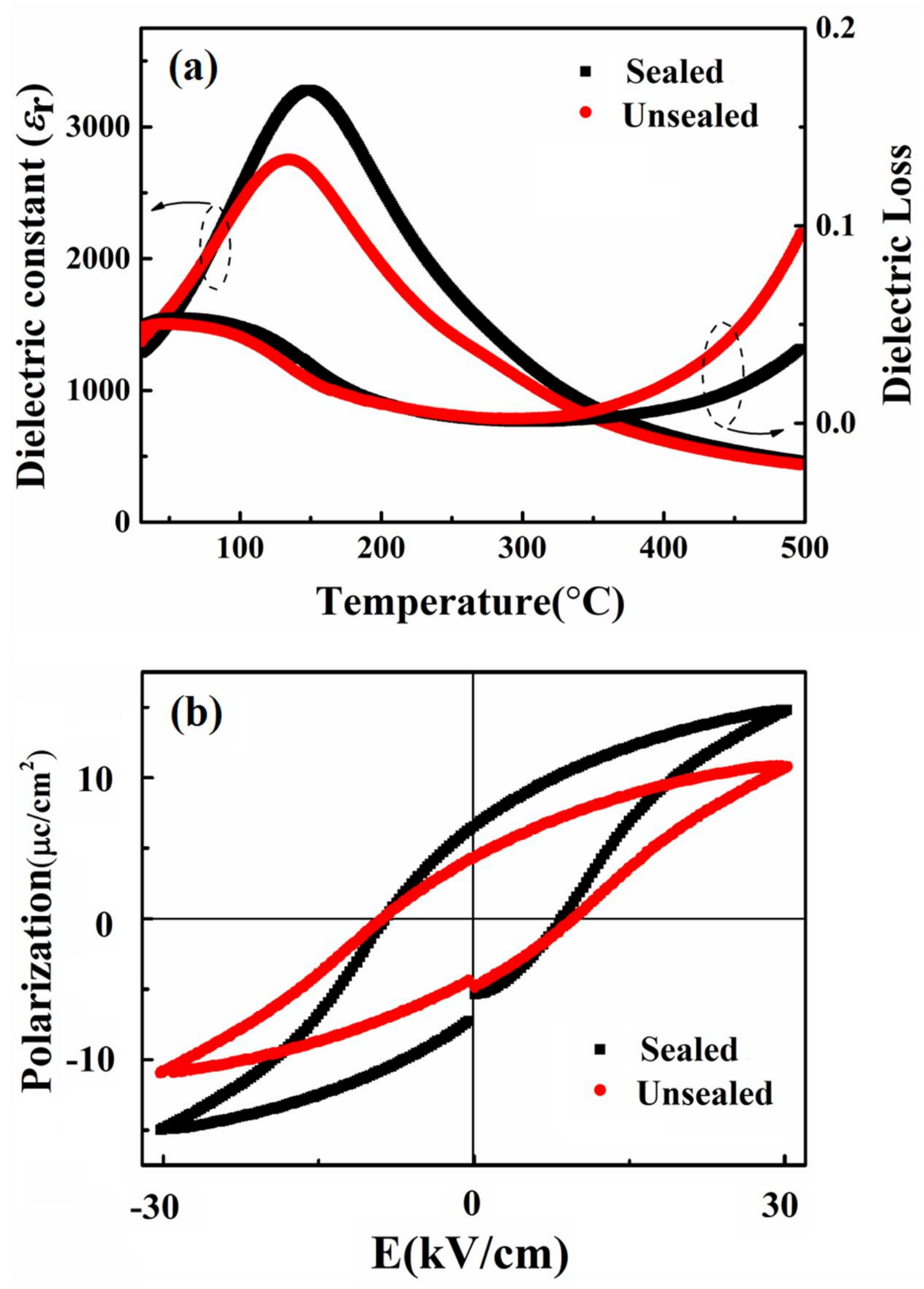

Figure 3 


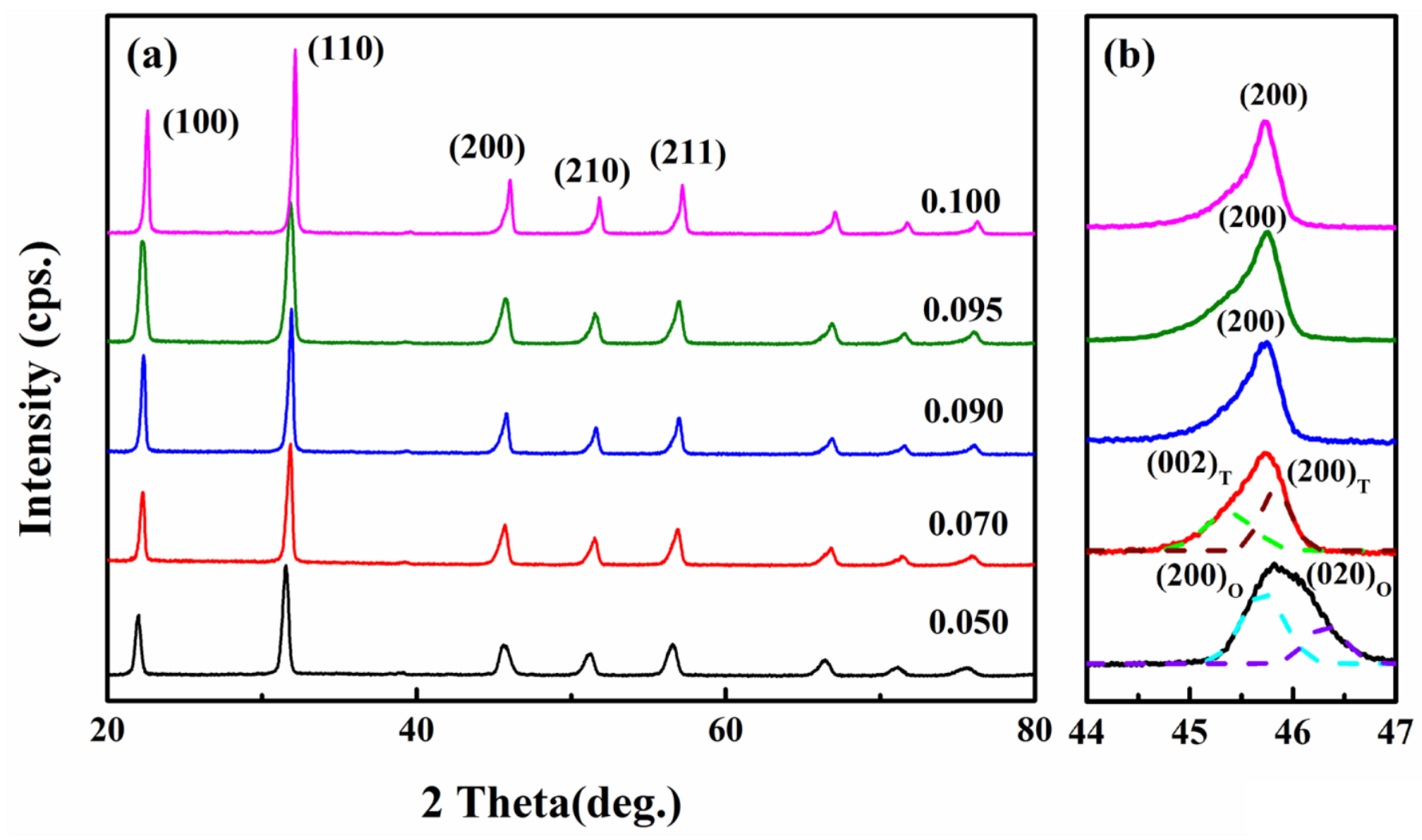

Figure 4 

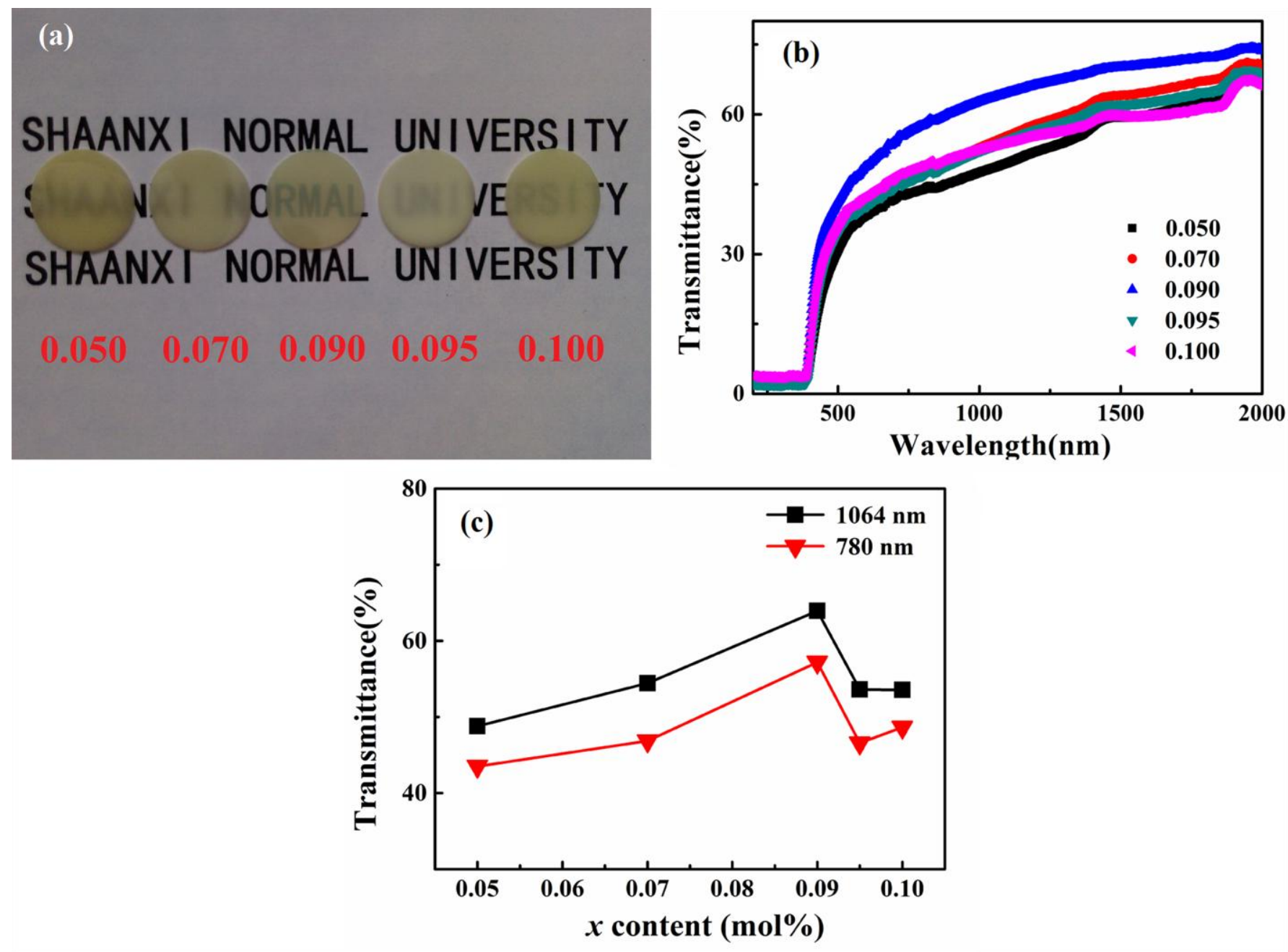

Figure 5 

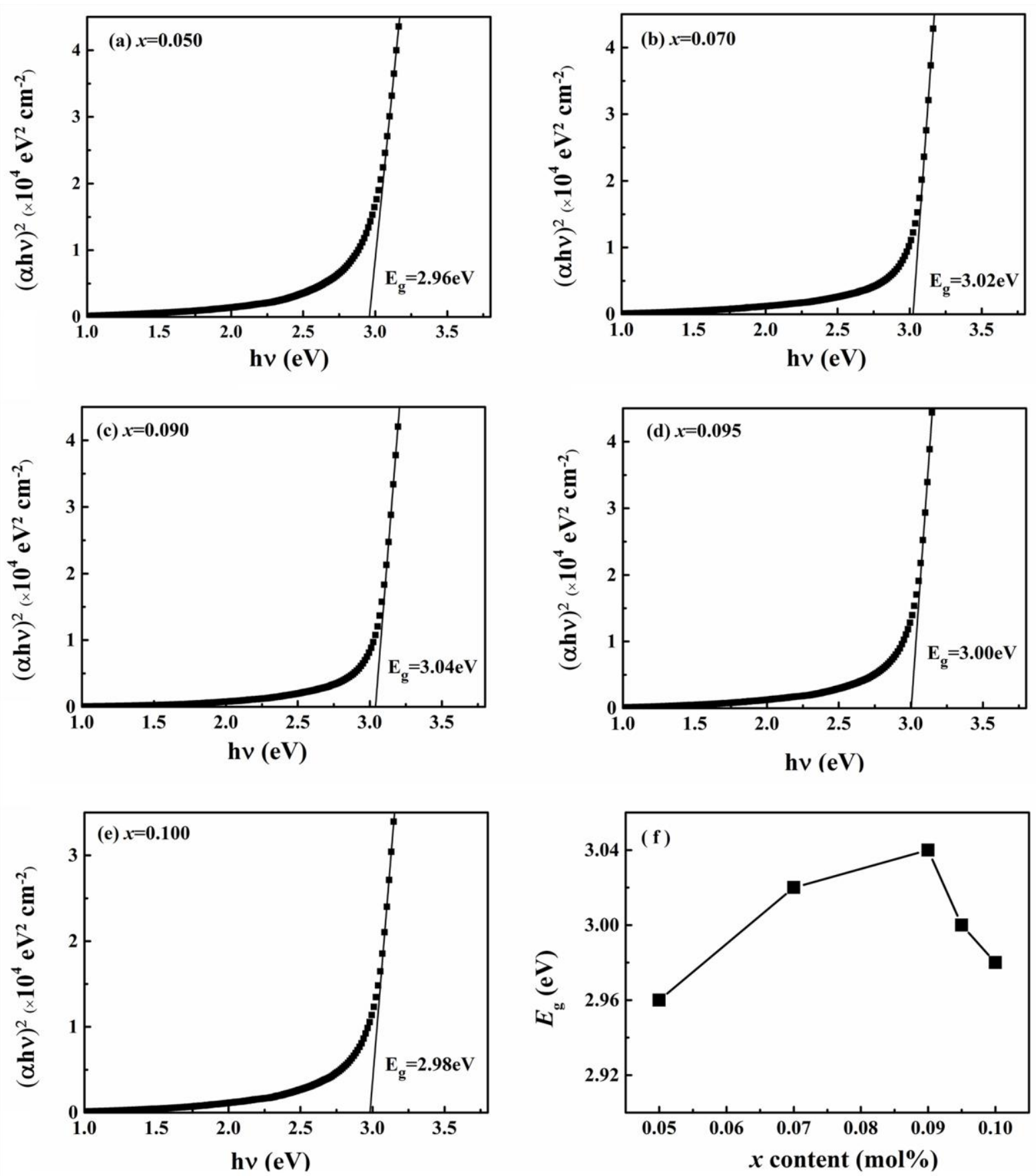

Figure 6 

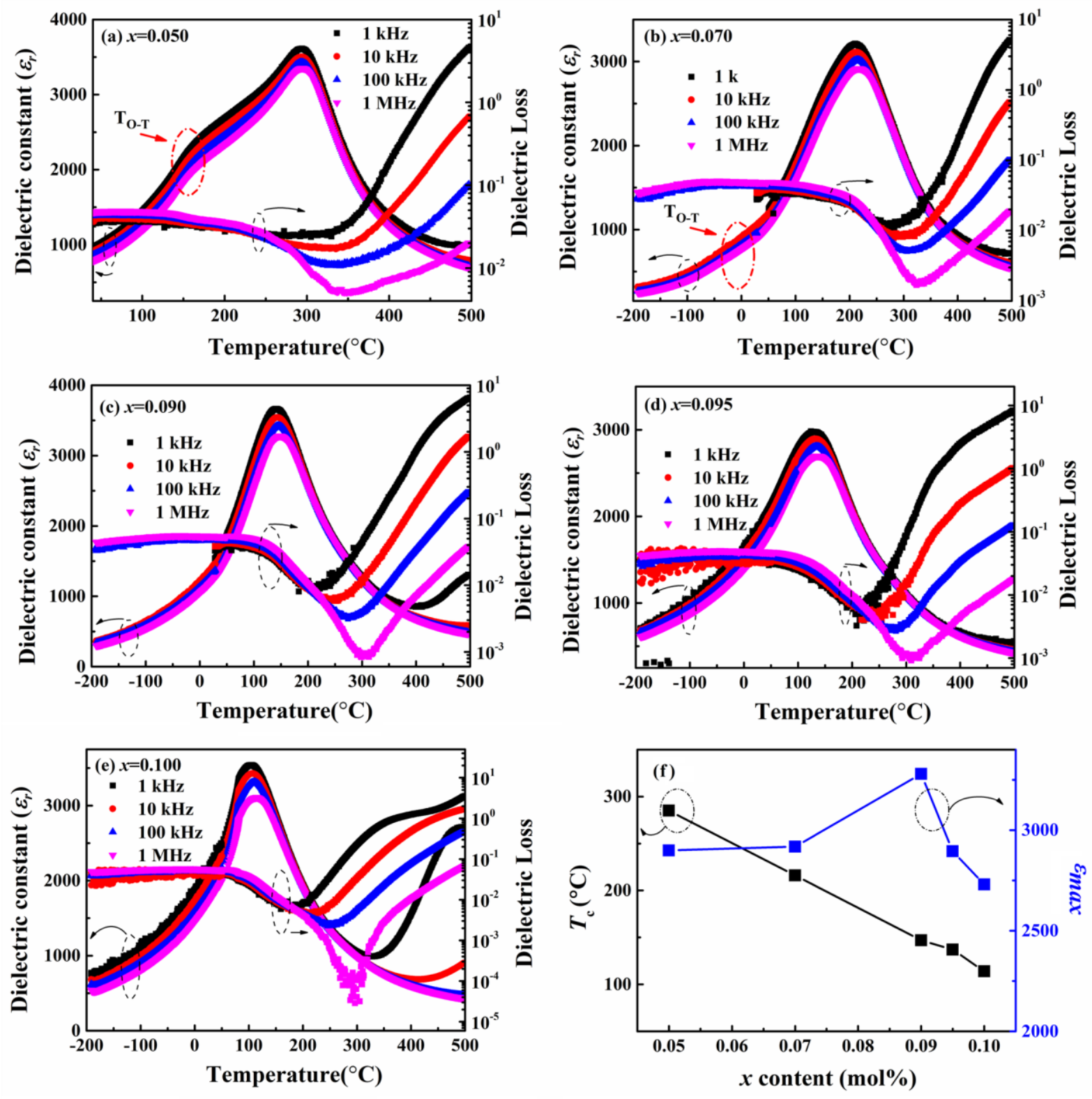

Figure 7 

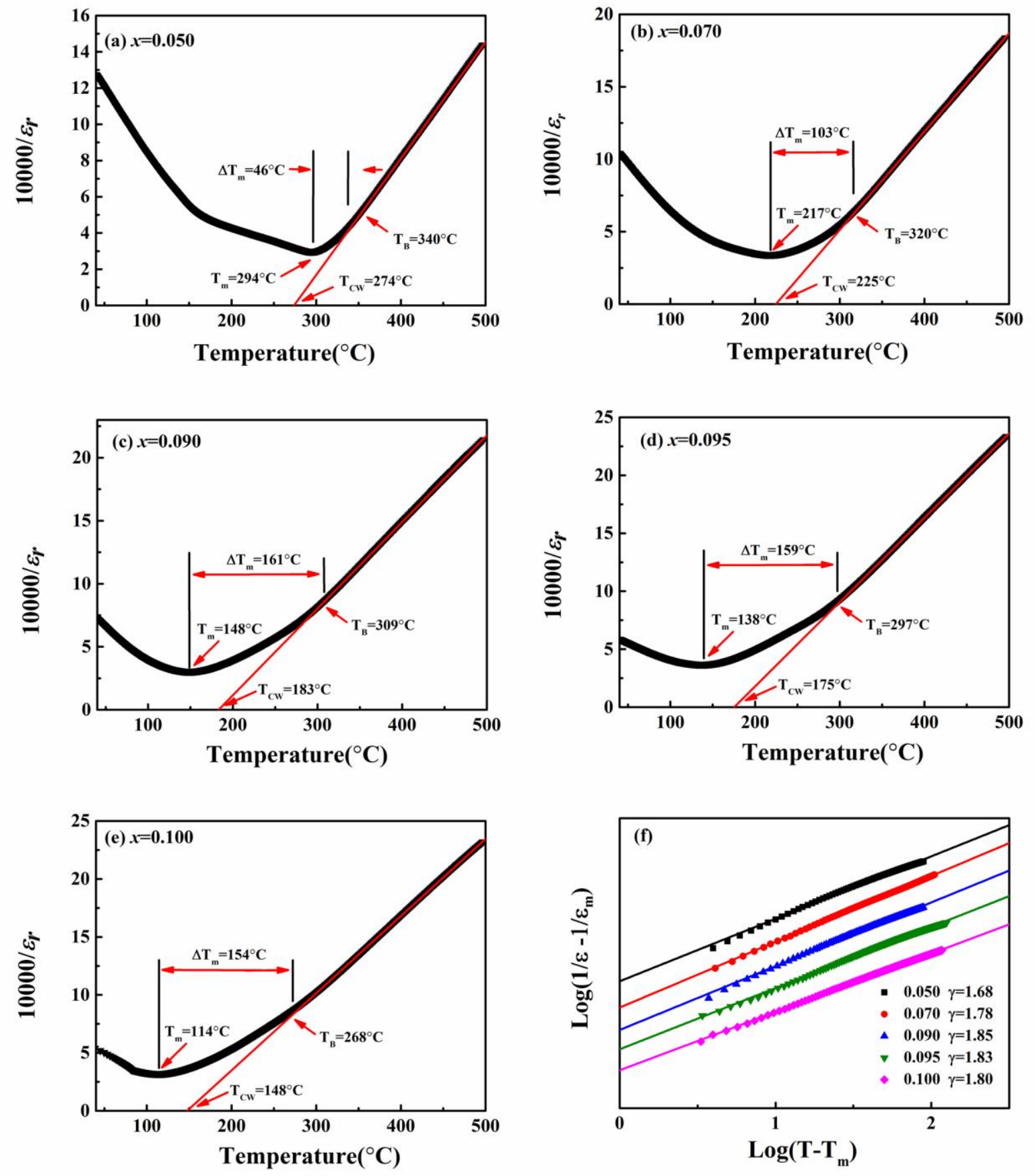

Figure 8 

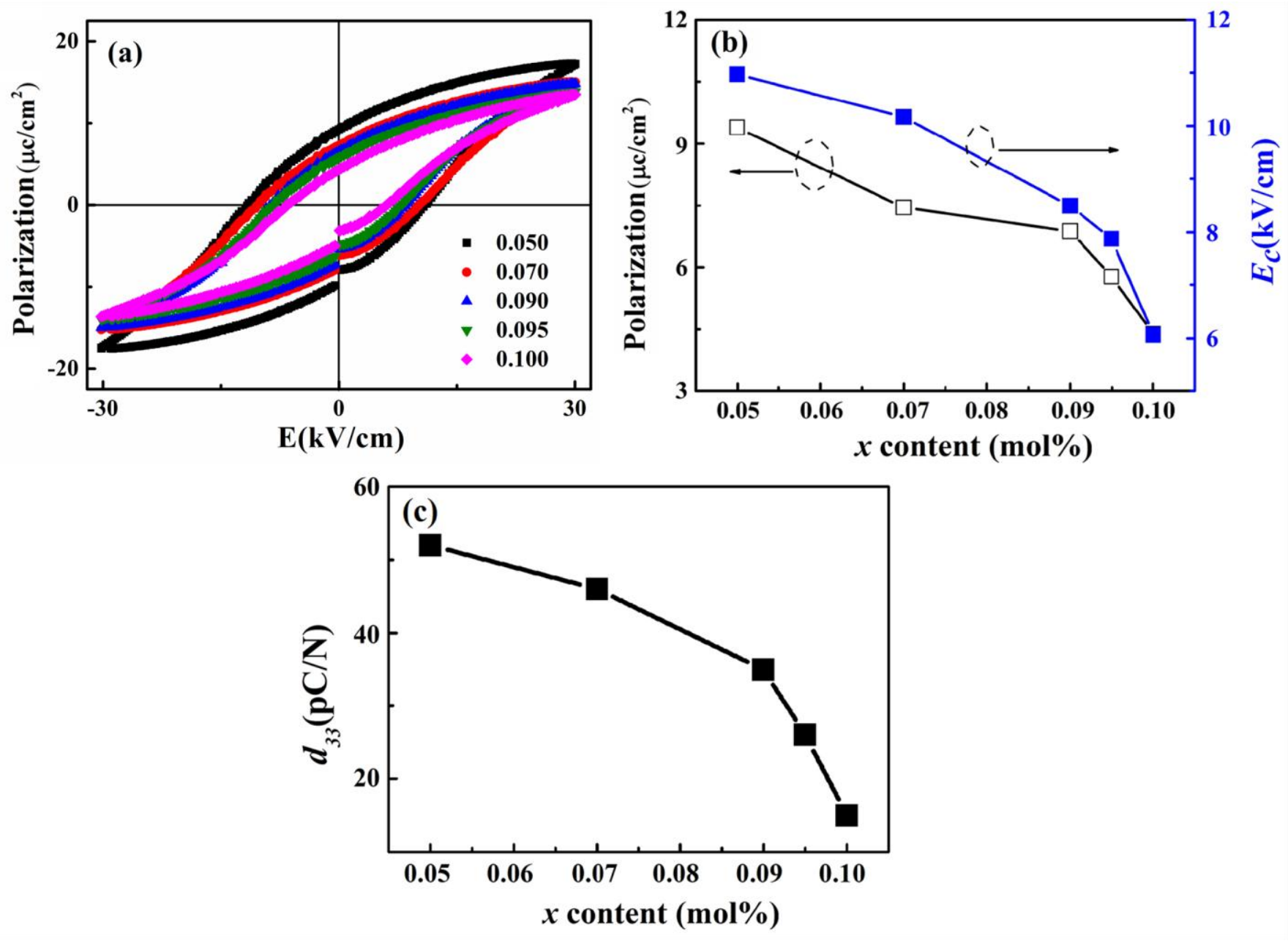

Figure 9 